\title{
Role of MAPK/JNK signaling pathway on the regulation of biological behaviors of MC3T3-E1 osteoblasts under titanium ion exposure
}

\author{
WEN-QING ZHU ${ }^{1,2^{*}}$, PAN-PAN MING ${ }^{3 *}$, SONG-MEI ZHANG ${ }^{4}$ and JING QIU ${ }^{1,2}$ \\ ${ }^{1}$ Department of Oral Implantology, Affiliated Hospital of Stomatology; ${ }^{2}$ Jiangsu Key Laboratory of Oral Disease; \\ ${ }^{3}$ Department of Stomatology, Sir Run Run Hospital, Nanjing Medical University, Nanjing, \\ Jiangsu 210029, P.R. China; ${ }^{4}$ Department of General Dentistry, Eastman Institute for \\ Oral Health, University of Rochester, Rochester, NY 14620, USA
}

Received November 27, 2019; Accepted August 18, 2020

DOI: $10.3892 / \mathrm{mmr} .2020 .11575$

\begin{abstract}
The oral cavity is a complex environment that is constantly undergoing remodeling. This provides a favorable electrolytic aqueous condition, which causes the corrosion of titanium implants and the release of titanium (Ti) ions. The accumulation of $\mathrm{Ti}$ ions in the peri-implant tissues may affect the osteogenesis process. Therefore, the present study aimed to investigate the possible effects of Ti ions on osteoblast physiology and its underlying mechanism, specifically the MAPK/JNK signaling pathway. In the present study, MC3T3-E1 osteoblasts were cultured the medium containing $10 \mathrm{ppm}$ Ti ions. Confocal laser scanning microscopy was used to analyze cell morphology and adhesion. Alkaline phosphatase (ALP) activity assay and western blotting were performed to evaluate the expression of proteins associated with osteogenesis such as Runx 2 and Osterix. Nuclear translocation of JNK, a key factor of the MAPK signaling pathway, was visualized and analyzed using immunofluorescence staining. The results showed that $10 \mathrm{ppm}$ Ti ions exerted negative effects on the biological behaviors of MC3T3-E1 cells, which exhibited reduced adhesion, ALP activity and osteogenic differentiation. It was also found that $10 \mathrm{ppm} \mathrm{Ti}$ ions activated the MAPK/JNK signaling pathway by promoting the nuclear translocation of JNK via phosphorylation. In addition, the inhibitory effects of
\end{abstract}

Correspondence to: Professor Jing Qiu, Department of Oral Implantology, Affiliated Hospital of Stomatology, Nanjing Medical University, 1 Shanghai Road, Nanjing, Jiangsu 210029, P.R. China

E-mail: qiujing@njmu.edu.cn

"Contributed equally

Abbreviations: Ti, titanium; ALP, alkaline phosphatase; Runx2, runt-related transcription factor 2; OSX, Osterix

Key words: titanium ions, osteoblast, MAPK/JNK signaling pathway
$10 \mathrm{ppm}$ Ti ions on MC3T3-E1 cells was found to be reversed by the JNK inhibitor SP600125. In conclusion, the preset study suggests that the MAPK/JNK signaling pathway serves a key role in the molecular mechanism underlying the changes in osteoblast behavior following Ti ion exposure. These findings may serve as a valuable reference point for the further in-depth exploration of peri-implant bone loss.

\section{Introduction}

Titanium (Ti) is one the most frequently applied materials for dental implants due to their excellent osteocompatibility, mechanical property and corrosion resistance (1-3). The oral cavity is a humid environment that provides a habitat for acid-producing bacteria, which causes low $\mathrm{pH}$ around the implants (4-6). This acidity triggers bio-corrosion, which induces Ti ion release to negatively affect osseointegration $(7,8)$. It has been previously reported that excessive Ti ions exert detrimental influences on bone cells, which can in turn negatively affect peri-implant bone remodeling and osseointegration (9). Following implantation, bone reconstruction around the implant can be achieved, which is heavily dependent on the delicate balance between bone resorption and formation. During this process, osteoclasts and osteoblasts interact with each other to maintain bone remodeling. As a possible noxious stimulus on bone cells, Ti ions released during the corrosion process or Ti nanoparticles escaped during surgery can disrupt this balance by activating osteoclasts whilst inhibiting osteoblasts (10-12). Osteoclast-induced bone resorption is associated with a number of factors, including parathyroid hormone, interleukin (IL)-17A and semaphorin 3A (13-15). Excessive titanium ion or nanoparticle accumulation can promote the expression of TNF- $\alpha$ and IL-6, both of which can provoke inflammation and osteoclastogenesis $(16,17)$. In terms of the osteoblastic bone formation, several novel regulators of osteoblast differentiation have been found, including caveolin-1 and Doublecortin-like kinase 1 (DCAMKL1, a serine/threonine kinase) that belongs to the CaM kinase family and shares homology with the neuronal microtubule binding protein doublecortin $(18,19)$. 
At present, studies reporting the effects of titanium corrosion products on osteoblasts are insufficient. A previous study reported that $10 \mathrm{ppm} \mathrm{Ti}$ ions, which is the minimum toxic concentration, was capable of suppressing the growth whilst promoting the nuclear translocation of Yes-associated protein in osteoblast-like MC3T3-E1 cells (20). Although the negative effect of $\mathrm{Ti}$ ion exposure has been explored in preliminary studies, the underlying regulatory mechanism of the effects mediated by excessive Ti ion accumulation during osteoblast differentiation remain poorly understood.

Many signaling pathways and key signaling molecules have been reported to regulate osteogenic differentiation. Bone morphogenetic protein, Wnt, Hippo and MAPK signaling pathways have all been previously demonstrated to serve important roles in regulating osteoblast physiology (21-26). Among these, the MAPK signaling cascade pathway is particularly important for processes including cell proliferation, apoptosis and differentiation by activating nuclear transcription factors (27). The MAPK family is comprised of a number of components, including JNK, ERK and p38. ERK1/2 has been previously associated with cell proliferation (28) whereas p38 tended to bias towards cell differentiation (29). JNK signaling has been shown to be extensively activated by oxidative stress, where it serves as a regulator of several life-cycle processes, including cell meiosis, mitosis, differentiation and energy metabolism (30). In particular, JNK activity is required for the initiation of early osteogenic differentiation in mesenchymal stem cells (MSCs) (31,32). By contrast, attenuation of JNK activity using JNK inhibitors was found to result in increased late stage osteogenic differentiation (33). These findings suggest that the MAPK/JNK signaling pathway serves a vital role throughout different stages of osteogenic differentiation. However, to the best of our knowledge, there remains an insufficient number of studies evaluating the relationship between elevated Ti ion levels and JNK activity, which may prove useful in clarifying the mechanism behind the effects of Ti ions on osteoblast behaviors. Consequently, the aim of the present study was to explore the role of the MAPK/JNK signaling pathway in the molecular mechanism underlying the effects of excessive $\mathrm{Ti}$ ion exposure on the biological characteristics of MC3T3-E1 osteoblasts.

\section{Materials and methods}

Cell culture. MC3T3-E1 cells, an osteoblast-like cell line, were obtained from the Cell Bank of Type Culture Collection of the Chinese Academy of Sciences and used as an in vitro model of osteoblast development for evaluating cellular responses, including attachment, proliferation and gene expression. MC3T3-E1 cells were cultured in $\alpha$-MEM containing $10 \%$ FBS and $1 \%$ penicillin/streptomycin (All Gibco; Thermo Fisher Scientific, Inc.) at $37^{\circ} \mathrm{C}$ in a humidified atmosphere under $5 \% \mathrm{CO}_{2}$. The culture medium was changed every two days, where cells were digested and passaged every time $80-90 \%$ confluence was reached. Titanium atomic absorption standard solution $(1,000 \mu \mathrm{g} / \mathrm{ml})$ was purchased from Sigma-Aldrich, Merck KGaA (cat. no. 274933). Cells co-cultured with or without 10 ppm Ti ions (diluted 100 times from the Titanium atomic absorption standard solution; $1,000 \mu \mathrm{g} / \mathrm{ml}$ ) or inhibitor of the MAPK/JNK pathway $(25 \mu \mathrm{M} \mathrm{SP} 600125)$ at $37^{\circ} \mathrm{C}$ in a humidified atmosphere under $5 \% \mathrm{CO}_{2}$ were denoted as the control, Ti, JNK inhibitor [cells co-cultured with inhibitor of the MAPK/JNK pathway $\left(25 \mu \mathrm{M}\right.$ SP600125) at $37^{\circ} \mathrm{C}$ in a humidified atmosphere under $\left.5 \% \mathrm{CO}_{2}\right]$ and $\mathrm{Ti}+\mathrm{JNK}$ inhibitor groups, respectively.

Cell adhesion and spreading assay. The initial cell seeding density into commercially pure titanium samples (Titanium atomic absorption standard solution; $1,000 \mu \mathrm{g} / \mathrm{ml}$ ) was $5 \times 10^{3}$ cells/well. Cells were pretreated with or without the JNK inhibitor SP600125 (cat. no. 8177; Cell Signaling Technologies, Inc.) for $1 \mathrm{~h}$ and then co-cultured with 0 or $10 \mathrm{ppm} \mathrm{Ti}$ ions for another $8 \mathrm{~h}$ at $37^{\circ} \mathrm{C}$ in a humidified atmosphere under $5 \% \mathrm{CO}_{2}$. Each sample was subsequently washed twice with PBS and fixed with $95 \%$ alcohol at $4^{\circ} \mathrm{C}$ overnight. $7 \mu \mathrm{l} / 2 \mathrm{ml}$ Rhodamine Phalloidin (Cytoskeleton, Inc.) was then prepared and added to the cells in the dark for $30 \mathrm{~min}$ at room temperature to achieve cytoskeleton staining. After rinsing the samples twice with PBS, $1 \mu \mathrm{l} / 2 \mathrm{ml}$ DAPI was added (cat. no. C1002; Beyotime Institute of Biotechnology) for $30 \mathrm{sec}$ for nuclei staining at room temperature. Each sample was observed at x200 magnification using a confocal laser scanning microscope (LSM710; Zeiss AG).

Alkaline phosphatase (ALP) activity assay. MC3T3-E1 cells $\left(2 \times 10^{5}\right.$ cells/well) were initially seeded into a 6 -well plate and cultured overnight at $37^{\circ} \mathrm{C}$ in a humidified atmosphere under $5 \% \mathrm{CO}_{2}$. After pretreatment with or without SP600125 for $1 \mathrm{~h}$ at $37^{\circ} \mathrm{C}$, cells were co-cultured with 0 or $10 \mathrm{ppm} \mathrm{Ti}$ ions (without SP600125) for a further 7 days to investigate the effect of $\mathrm{Ti}$ ions on cell differentiation. Each sample was washed with PBS twice and fixed with $95 \%$ alcohol at $37^{\circ} \mathrm{C}$ for $30 \mathrm{~min}$. ALP staining was determined using ALP Stain Kit (cat. no. D001-1-1; Nanjing Jiancheng Bioengineering Institute) and the duration of this staining procedure was about $30 \mathrm{~min}$ at $37^{\circ} \mathrm{C}$. Then the images were then observed and captured using an Epson Perfection V30 scanner (Seiko Epson Corporation). ALP activity was analyzed using an ALP Assay Kit (cat. no. A059-2-2; Nanjing Jiancheng Bioengineering Institute) according to the manufacturer's protocols. Total protein content was determined using bicinchoninic acid (BCA) protein assay kit (Nanjing KeyGen Biotech Co., Ltd.). ALP activity relative to that of control was calculated after normalization to the total protein content.

Western blotting. The initial cell seeding density of MC3T3-E1 cells was $2 \times 10^{5}$ cells/well in a 6-well plate. After 7 days culture, cell proteins were extracted using RIPA buffer (cat. no. P0013B; Beyotime Institute of Biotechnology). The quantitation of total protein was performed using a BCA protein assay kit (Nanjing KeyGen Biotech Co., Ltd.). Protein lysates $(20 \mu \mathrm{g})$ were separated by $10 \%$ SDS-PAGE and transferred to polyvinylidene difluoride (PVDF) films. The membranes were then blocked using 5\% non-fat dry milk for $1 \mathrm{~h}$ at room temperature before incubation serially with primary antibodies overnight at $4{ }^{\circ} \mathrm{C}$ and secondary antibodies for $2 \mathrm{~h}$ at room temperature. After rinsing three times with PBS to remove the residual antibodies, the protein bands were visualized using ECL Western Blot Kit (EMD Millipore). The primary antibodies used in the present study were as 

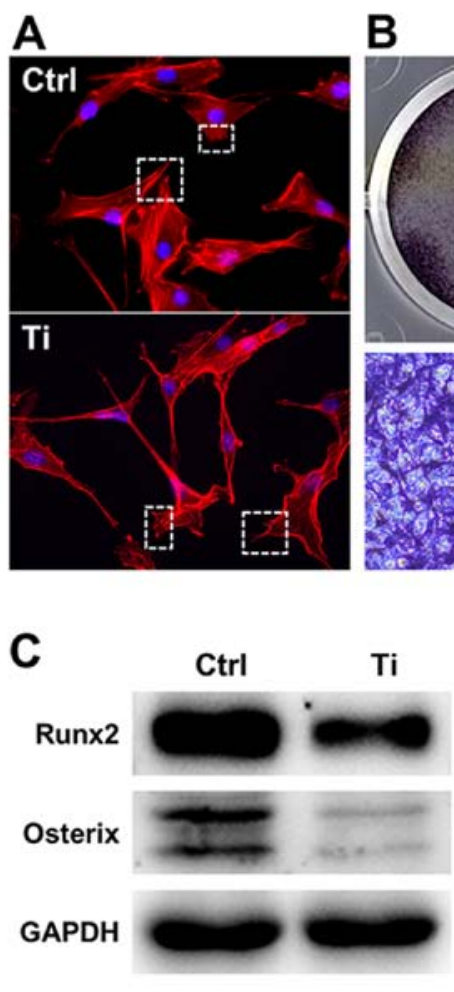

B
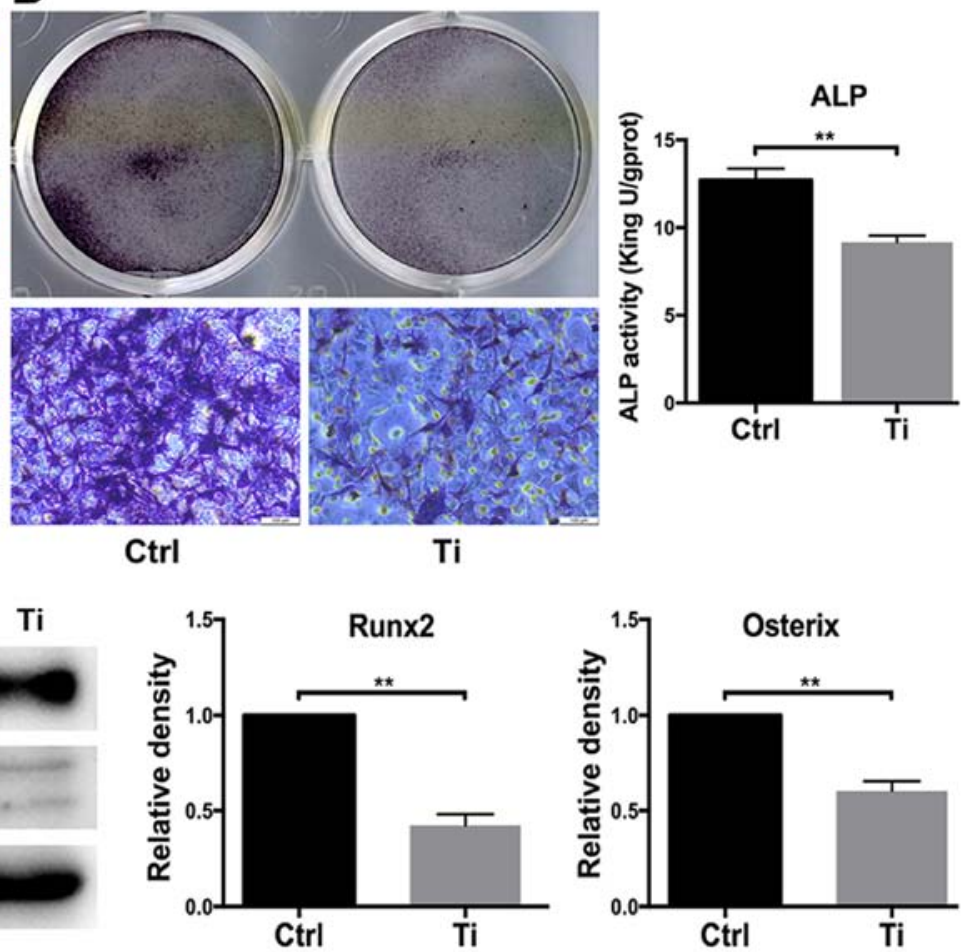

Figure 1. Effects of $10 \mathrm{ppm}$ Ti ions on the biological characteristics of MC3T3-E1 osteoblasts. (A) Cell adhesion and spreading in the control and Ti groups observed using a confocal laser scanning microscope. Magnification, x200. (B) ALP staining and activity in the control and Ti groups. Magnification, x100. (C) Protein expression levels of Runx 2 and OSX in the control and Ti groups. Quantification was performed by ImageJ software. Results were presented as the mean \pm SD. ${ }^{* *} \mathrm{P}<0.01$. Ctrl, control; Ti, titanium ions; ALP, alkaline phosphatase; Runx2, Runt-related transcription factor 2; OSX, osterix.

follows: Runt-related transcription factor 2 (1:1,000, Runx2; cat. no. 12556; Cell Signaling Technology, Inc.), Osterix (1:1,000, OSX; cat. no. ab22552; Abcam), JNK $(1: 1,000$, cat. no. 9252; Cell Signaling Technology, Inc.), phosphorylated (p)-JNK (1:1,000, cat. no. 4668; Cell Signaling Technology, Inc.) and GAPDH (1:3,000, cat. no. BM1623; Wuhan Boster Biological Technology, Ltd.). The secondary antibodies used were as follows: horseradish peroxidase-conjugated goat anti-rabbit IgG (1:1,000, cat. no.ZB-2301;ZSGB-BIO; OriGene Technologies, Inc.) and horseradish peroxidase-conjugated goat anti-Mouse IgG (1:1,000, cat. no. AP124P; EMD Millipore). Protein quantification was analyzed using ImageJ software (version k1.45; National Institutes of Health).

Immunofluorescence staining for JNK nuclear translocation. The initial cell seeding density of MC3T3-E1 cells was $1 \times 10^{5}$ cells/well onto 24 -well glass coverslips $(13 \mathrm{~mm}$ diameter) in a 12-well plate. Cells were pretreated with or without SP600125 for $1 \mathrm{~h}$ and then co-cultured with 0 or $10 \mathrm{ppm}$ Ti ions for another 3 days at $37^{\circ} \mathrm{C}$ in a humidified atmosphere under $5 \% \mathrm{CO}_{2}$. Afterwards, cells were washed in PBS, fixed with $4 \%$ paraformaldehyde for $15 \mathrm{~min}$ at $4{ }^{\circ} \mathrm{C}$, treated with $0.5 \%$ Triton $\mathrm{X}-100$ for $15 \mathrm{~min}$ at room temperature to increase permeability and then blocked with $10 \%$ goat serum (cat. no. 005-000-121; Jackson ImmunoResearch Laboratories, Inc.) for $1 \mathrm{~h}$ at $37^{\circ} \mathrm{C}$. The cells were subsequently incubated with primary antibodies at $4^{\circ} \mathrm{C}$ overnight, followed by incubation with FITC-conjugated secondary antibodies for $1 \mathrm{~h}$ at $37^{\circ} \mathrm{C}$. All nuclei were stained with $1 \mu \mathrm{l} / 2 \mathrm{ml}$ DAPI for
$3 \mathrm{~min}$ at room temperature before the subcellular localization of proteins were visualized at x200 magnification and analyzed using fluorescence microscopy (Leica DM4000M; Leica Microsystems $\mathrm{GmbH}$ ). The primary and secondary antibodies used for immunofluorescence were as follows: P-JNK (1:100; cat. no. 4668; Cell Signaling Technology, Inc.), DyLight 549 AffiniPure goat anti-rabbit IgG (H+L; 1:200; cat no. A23320; Abbkine Scientific Co., Ltd.).

Statistical analysis. Data were analyzed using the SPSS 22.0 software (IBM Corp.) and presented as the mean \pm SD. Group differences were analyzed using one-way ANOVA followed by Tukey's post hoc test. ${ }^{*} \mathrm{P}<0.05$ and ${ }^{* *} \mathrm{P}<0.01$ were considered to indicate statistically significant differences.

\section{Results}

Inhibition of osteoblast behavior following Ti ion exposure. The morphology of osteoblasts serves a key role in regulating cell proliferation and differentiation (34). Cell adhesion and spreading were observed after MC3T3-E1 cells were treated with 0 or $10 \mathrm{ppm}$ Ti ions for $8 \mathrm{~h}$ (Fig. 1A). Compared with the control group, osteoblasts that were treated with $10 \mathrm{ppm}$ Ti ions exhibited disordered extension of pseudopodia, disorganized cell spreading and poor substrate adherence (Fig. 1A), suggesting that $10 \mathrm{ppm}$ Ti ions suppressed the first phase of osteoblast differentiation. Since ALP is widely considered to be a marker of early-stage osteoblast differentiation (35), ALP staining and activity was next quantified in MC3T3-E1 cells. 


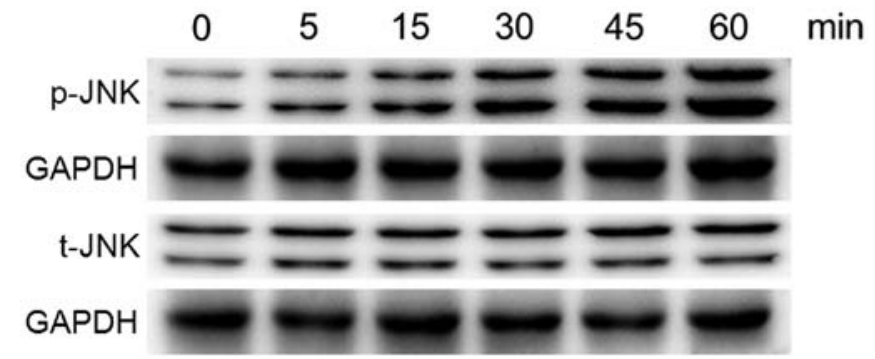

Figure 2. Protein expression levels of total JNK and JNK phosphorylation in MC3T3-E1 osteoblasts following treatment with or without $10 \mathrm{ppm}$ titanium ions at all time points up to $60 \mathrm{~min}$. t-, total; p-, phosphorylated.

ALP staining in the Ti group was found to be markedly weaker compared with that in the control group, suggesting that $10 \mathrm{ppm}$ Ti ions inhibited osteoblast differentiation. A similar finding was obtained from the levels of ALP activities, which was significantly lower it the Ti group compared with those in the control group (Fig. 1B). Runx2 and OSX are vital transcription factors for osteoblast differentiation (36). Therefore, the expression levels of these two proteins were measured by western blotting to analyze cell differentiation. After 7 days of culture, Runx 2 and OSX expression was revealed to be downregulated in MC3T3-E1 cells in the Ti group compared with that in the control group, indicating that $10 \mathrm{ppm}$ Ti ions can inhibit the early mineralization process of MC3T3-E1 cells (Fig. 1C). Therefore, these observations suggest that $10 \mathrm{ppm} \mathrm{Ti}$ ions can disrupt the biological behaviors of osteoblasts, which may be due to the inhibition of cell adhesion in the early stages of differentiation.

Activation of the MAPK/JNK signaling pathway in osteoblasts following Ti ion exposure. MC3T3-E1 cells were treated with $10 \mathrm{ppm} \mathrm{Ti}$ ions at the early time points up to $60 \mathrm{~min}$, following which the phosphorylation levels of JNK were analyzed by western blotting, since the phosphorylation process is rapid (Fig. 2). The levels of p-JNK was found to be markedly increased following exposure to $10 \mathrm{ppm}$ Ti ions within $60 \mathrm{~min}$. However, the total protein expression of JNK remained stable. These results suggest that the MAPK/JNK signaling pathway was activated after treatment with $10 \mathrm{ppm}$ Ti ions.

Immunofluorescence assay was used to confirm the effects of Ti ions on the nuclear translocation of JNK. It was shown that p-JNK is mainly localized in the cytoplasm (Fig. 3). After being exposed to $10 \mathrm{ppm}$ Ti ions for $72 \mathrm{~h}$, p-JNK staining became stronger and was more localized in the nuclei compared with that in the control group, suggesting that JNK signaling has been activated (Fig. 3). These results suggested that $10 \mathrm{ppm}$ Ti ions can activate the MAPK/JNK signaling pathway by promoting the phosphorylation and subsequent nuclear translocation of JNK.

Key role of MAPK/JNK signaling pathway in the regulation of Ti ion-induced effects in osteoblasts. SP600125, a MAPK/JNK inhibitor, was used to explore the role of this signaling pathway in the regulation of Ti ion-induced effects in MC3T3-E1 osteoblasts. The effects of SP600125 on the nuclear translocation of p-JNK (Fig. 3), cell adhesion (Fig. 4) and cell differentiation (Figs. 5 and 6) were separately investigated in MC3T3-E1 cells following Ti ion exposure.

As aforementioned, $10 \mathrm{ppm}$ Ti ions were demonstrated to promote the nuclear localization of p-JNK (Fig. 3). Following pretreatment with SP600125 for $1 \mathrm{~h}$, the distribution of p-JNK in MC3T3-E1 cells became more dispersed, where the nuclear staining was less intense in the JNK inhibitor group compared with that in the control group. Furthermore, after being treated with Ti ions, nuclear $\mathrm{p}-\mathrm{JNK}$ staining in the Ti + JNK inhibitor group was found to be less overlapped compared with that in the Ti group, that is, following treatment with $\mathrm{Ti}$ ions, there was less nuclear $\mathrm{p}-\mathrm{JNK}$ red staining overlapping with blue DAPI in the $\mathrm{Ti}+\mathrm{JNK}$ inhibitor group compared with that in the Ti group. These results suggested that $10 \mathrm{ppm}$ Ti ions activated the MAPK/JNK signaling pathway in MC3T3-E1 cells.

As shown in Fig. 4, 10 ppm Ti ions inhibited the spreading of MC3T3-E1 cells compared with that in the control group. Following pretreatment with SP600125, cells in the Ti + JNK inhibitor group were demonstrated to extended more pseudopodia and spread more evenly (white boxes) compared with those in the Ti group, suggesting that cell adhesion and spreading ability were preserved following Ti ion exposure when the MAPK/JNK pathway was inhibited. As shown in Fig. 5, 10 ppm Ti ions suppressed the ALP activities in osteoblasts compared with those in the control group. Following treatment with SP600125, the ALP activities in the Ti + JNK inhibitor group was found to be significantly improved compared with those in the Ti group $\left(\mathrm{P}=0.0378,{ }^{*} \mathrm{P}<0.05\right)$. The expression levels of Runx 2 and OSX proteins after Ti ion exposure were also revealed to be significantly downregulated compared with those in the control group (Fig. 6). When the MAPK/JNK pathway was blocked by SP600125, the reduced expression levels of Runx 2 and OSX caused by Ti treatment were partially reversed, which offset some of the adverse effects mediated by the Ti ions. Therefore, these findings suggest that $10 \mathrm{ppm}$ Ti ion regulated the osteoblast behaviors through activating the MAPK/JNK signaling pathway.

\section{Discussion}

Although there has been rapid developments in the dental implantology field over the past decades, attention need to be paid on the complications associated with dental implants $(37,38)$. Many concerns have been previously raised about the response of the oral cavity to corrosive products generated from titanium-based dental implants $(39,40)$. Noumbissi et al (41) previously reported that titanium implant corrosion was a potential risk factor for the establishment and progression of peri-implant mucositis and peri-implantitis. These corrosive products, most of which are comprised of free Ti ions, are typically released from the damaged passivation film of the titanium (8). Previous evidence has shown that excessive Ti ions and nanoparticles can hinder cell growth and division in the tissues surrounding the implants (42). In addition, inflammatory cells or phagocytic cells around the implants, including osteoclasts, macrophage and foreign body giant cells, can be activated following Ti ion exposure. This leads to immune system activation, which may influence bone formation and increase the risk of implant failure $(43,44)$. 


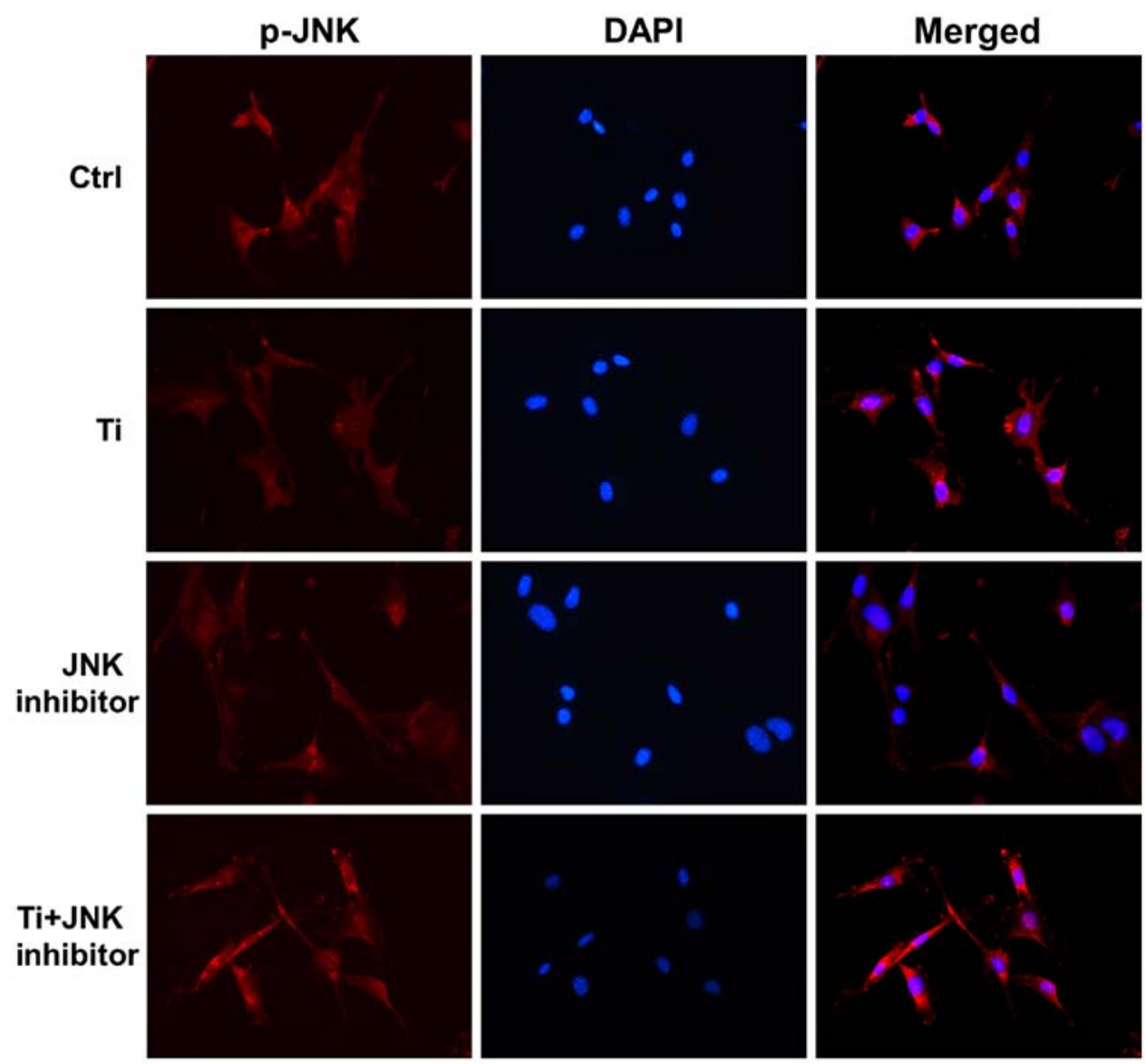

Figure 3. Activation of MAPK/JNK signaling pathway following titanium ion exposure. Immunofluorescence staining for p-JNK (red) and nuclei (blue) were performed to assess the nuclear translocation of p-JNK in MC3T3-Elosteoblasts. Ctrl, control; p-, phosphorylated.
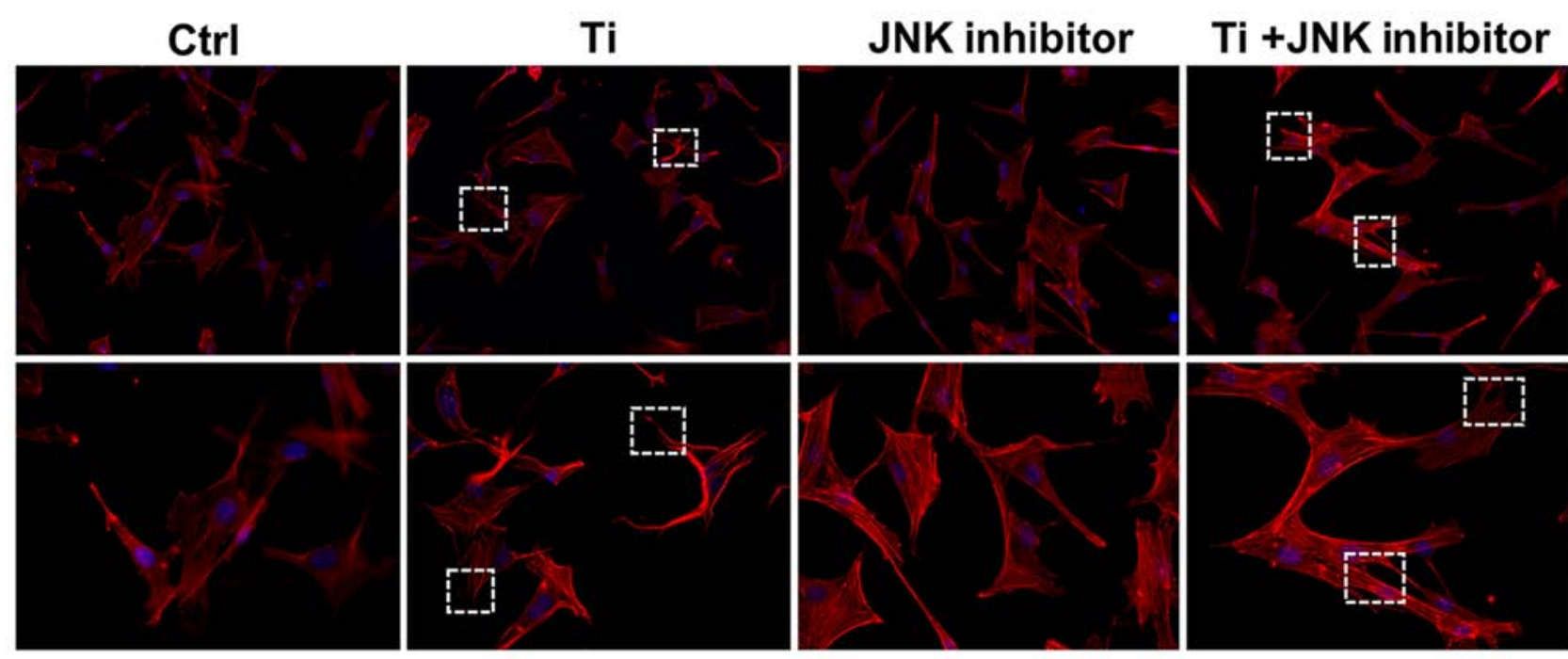

Figure 4. Role of MAPK/JNK signaling pathway in regulating cell adhesion and spreading of MC3T3-E1 osteoblasts following Ti ion exposure. Cell adhesion and spreading was observed using a confocal laser scanning microscope. The red staining in fluorescence represented cytoskeleton and the blue staining represented nuclei. Magnification, x100 (upper row) and x200 (lower row). Ti, titanium.

Although some studies have reported Ti ions-induced cytotoxicity in bone cells, the exact underlying mechanism remains unclear.

A previous study has demonstrated that $10 \mathrm{ppm}$ Ti ions was a toxic concentration for osteoblast proliferation (20). In the present study, the effects of $10 \mathrm{ppm} \mathrm{Ti}$ ions on osteoblast adhesion and early differentiation characteristics were investigated further. The results demonstrated that $10 \mathrm{ppm}$ Ti ions could restrict the extension of osteoblast pseudopodia and inhibit cell spreading. Osteoblast differentiation covers osteogenic commitment and osteogenic differentiation (45). During the osteogenic commitment process, Runx 2 is considered to 

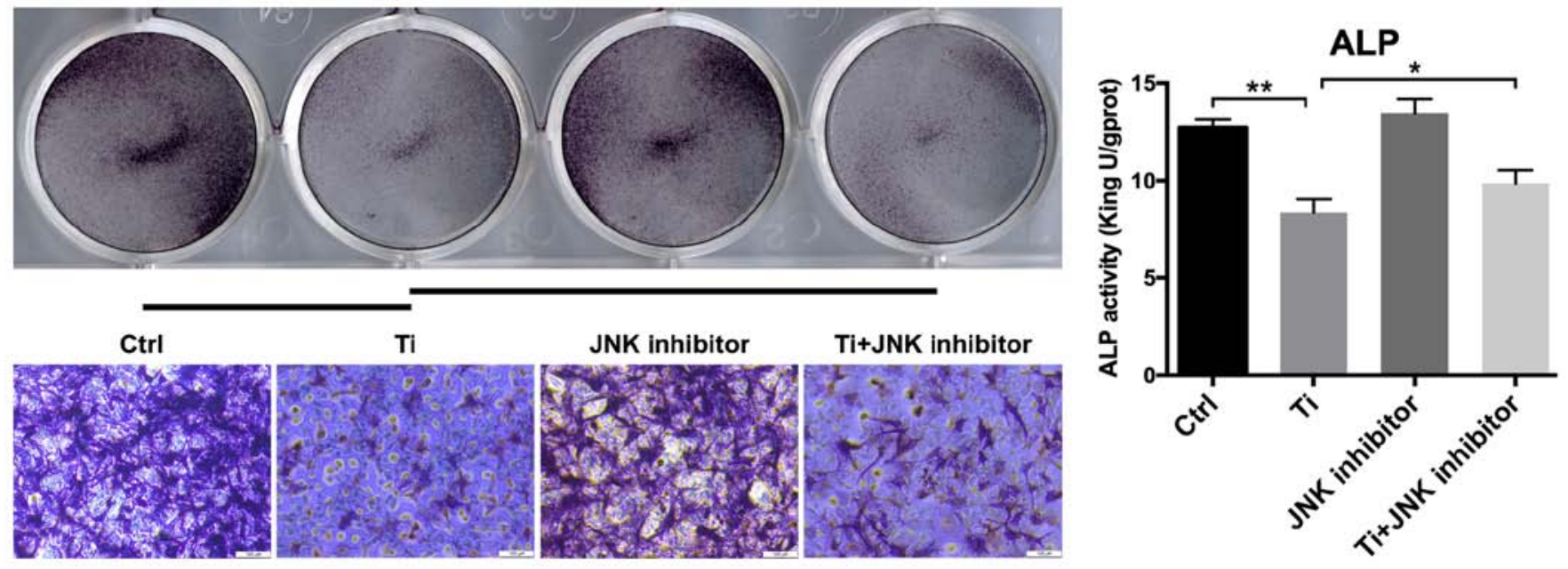

Figure 5. Role of MAPK/JNK signaling pathway on the regulation of osteogenic differentiation of MC3T3-E1 osteoblasts following Ti ion exposure. ALP staining and activity in the control, Ti group, JNK inhibitor and Ti + JNK inhibitor groups. Magnification, $\mathrm{x} 100 .{ }^{*} \mathrm{P}<0.05$ and ${ }^{* * *} \mathrm{P}<0.01$. Ctrl, control; ALP, alkaline phosphatase; ti, titanium.
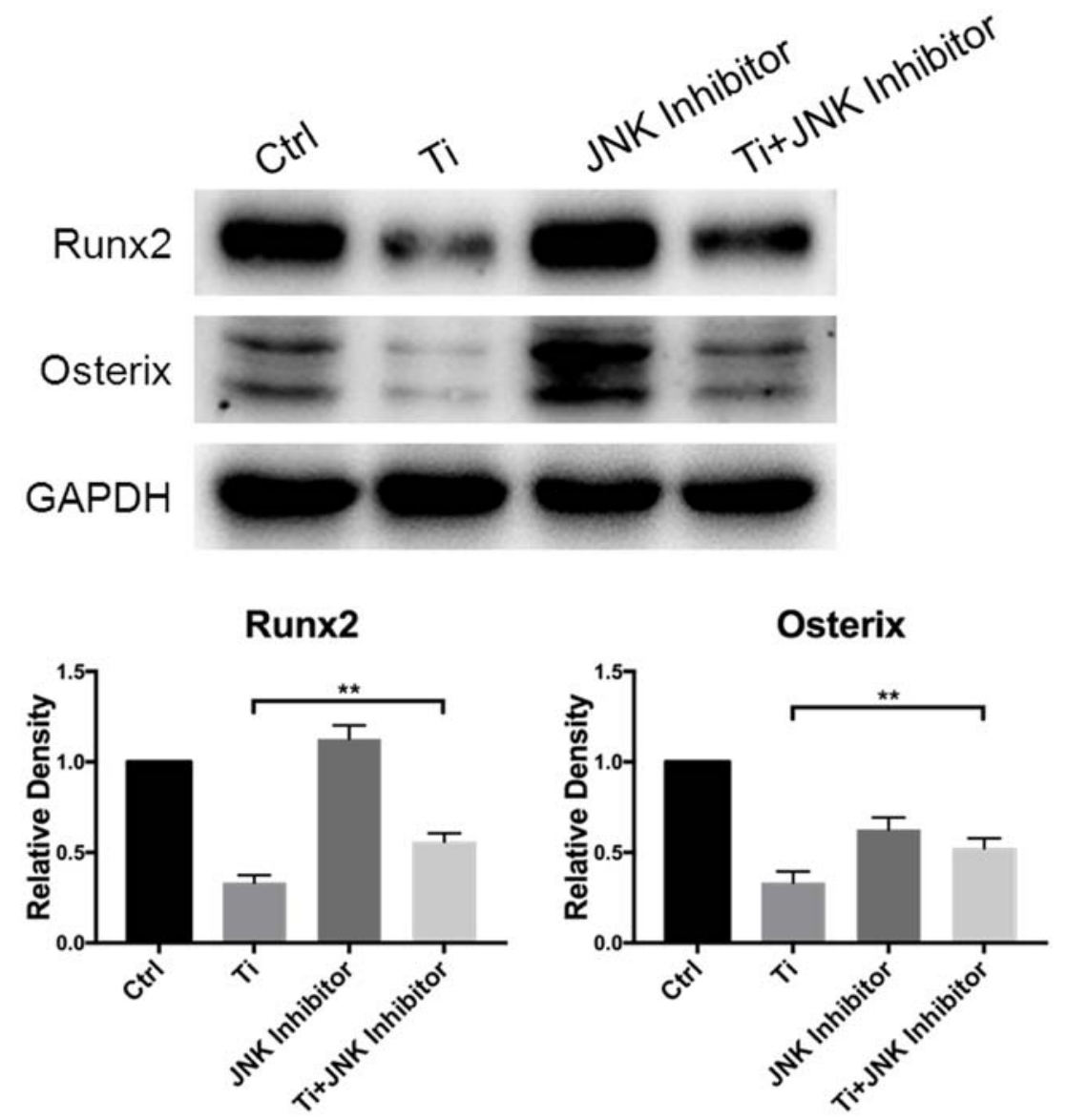

Figure 6. Role of the MAPK/JNK signaling pathway in the regulation of osteogenic differentiation of MC3T3-E1 osteoblasts following Ti ion exposure. Protein expression of Runx 2 and OSX in the control, Ti, JNK inhibitor and Ti + JNK inhibitor groups were measured. Quantification was performed using the ImageJ software. Results were presented as the mean $\pm \mathrm{SD}$. ${ }^{* *} \mathrm{P}<0.01$. Ti, titanium; Runx2, Runt-related transcription factor 2; OSX, osterix.

be one of the core transcription factors (46), whilst ALP and OSX are considered to be specific markers for the osteogenic differentiation process $(47,48)$. Analysis of ALP activity and western blotting showed that the expression of these osteogenic markers was downregulated following treatment with $10 \mathrm{ppm}$ Ti ions compared with those in control. These results were consistent a previous finding, which also showed that $10 \mathrm{ppm}$ Ti ions could inhibit proliferation of osteoblasts (20).

MAPK signaling pathway has been recognized as an important regulator of osteoblast differentiation and bone mass $(49,50)$. The upstream stimulation can activate the key components of the MAPK signaling pathway by 
post-translational modifications, including phosphorylation and acetylation (51). This then translates into downstream cascade reactions that can be triggered to regulate biological processes in the nucleus (52). The role of the MAPK signaling pathway on osteogenic function is garnering increasing research attention (53). A previous study has also demonstrated that JNK and ERK, which are key components of the MAPK signaling pathway, could serve as regulators of osteoblast physiology following fluoride exposure (26).

In the present study, the effects of Ti ions on the MAPK/JNK signaling pathway and changes in the phosphorylation status of JNK were investigated in MC3T3-E1 osteoblasts. The level of JNK phosphorylation in MC3T3-E1 osteoblast was shown to be increased after treatment with $10 \mathrm{ppm}$ Ti ions within $60 \mathrm{~min}$, whilst the total JNK expression remained unchanged. Nuclear translocation of $\mathrm{p}$-JNK following exposure to Ti ions was investigated further. Due to the rapid phosphorylation process, total intracellular protein expression frequently remains unchanged. The nuclear translocation status of p-JNK can be applied to independently measure the activity of JNK (54). Therefore, p-JNK was focused upon for the immunofluorescence staining to investigate the nuclear translocation process. As shown in Fig. 3 merged image, it was found that the red coverage area in the blue core was greater in the Ti group compared with the control group, suggesting that the localization of $\mathrm{p}-\mathrm{JNK}$ seemed to shift from the cytoplasm into the nucleus in cells treated with $10 \mathrm{ppm}$ Ti ions compared with that in the control group. A previous study demonstrated that JNK can be activated by dual phosphorylation at the threonine (Thr 183) and tyrosine (Tyr 185) residues (55). p-JNK can in turn activate the transcription factor c-Jun by phosphorylation, which is known to form the activator protein-1 transcription complex with c-Jun's principal dimerization partner, c-Fos (56). This complex finally binds to specific DNA sequences at target promoters to regulate the expression of associated genes that participate in the differentiation function of osteoblasts (57). In the present study, JNK was activated by $\mathrm{Ti}$ ions as the upstream stimulation, where the activated JNK induced the reactions of nuclear-localized transcription factors to influence the expressions of osteogenic markers (Figs. 2 and 3). However, the role of the MAPK/JNK signaling pathway in the $\mathrm{Ti}$ ion-induced osteoblast characteristics requires further study.

To ascertain the role of JNK in the regulation of osteoblast behaviors following Ti ion exposure further, subsequent experiments were performed by inhibiting JNK using the inhibitor SP600125. SP600125 is a common competitive inhibitor of JNK that can inhibit the phosphorylation of c-Jun, which have been used in many in vitro and in vivo studies $(58,59)$. Unlike small interfering RNAs or short hairpin RNAs products, which are recognized as powerful tools for targeted gene silencing in cells, SP600125 can partially reduce JNK expression rather than completely knocking it out. Therefore, residual amounts of JNK expression remained a possibility following the use of the JNK inhibitor in this study. In MC3T3-E1 osteoblasts pretreated with SP600125, a reduced number of p-JNK molecules went into the nuclei in the Ti $+\mathrm{JNK}$ inhibitor group compared with that in the Ti group. Importantly, the morphology of osteoblast adhesion was found to be improved when JNK was blocked in cells exposed to Ti ions, suggesting the ordered extension of the pseudopodia. In addition, the levels of osteogenic markers were revealed to be significantly upregulated when JNK was inhibited in cells exposed to Ti ions, including the increased activity of ALP, Runx 2 and OSX expression. These results demonstrated that the JNK signaling significantly regulated osteoblast behaviors under Ti ion exposure, such that JNK inactivation could attenuate the negative effect of Ti ions on osteoblast adhesion and osteogenic differentiation.

In conclusion, results from the present study demonstrated the negative effects of $10 \mathrm{ppm} \mathrm{Ti}$ ions on osteoblast physiology. It was shown that $10 \mathrm{ppm} \mathrm{Ti}$ ions can promote JNK activation by phosphorylation, which could in turn serve a key role in the regulation of Ti ion-induced cytotoxicity in osteoblasts. Therapeutic interventions that target JNK signaling may therefore improve the function of osteoblasts. These findings may serve as a valuable reference for the further in-depth exploration of the impact of $\mathrm{Ti}$ ions on titanium implant osseointegration and peri-implant bone loss in vivo, where the mechanism of JNK signaling involved in regulating bone formation after Ti ion exposure could be explored further.

\section{Acknowledgements}

\section{Not applicable.}

\section{Funding}

The present study was supported by the National Natural Science Foundation of China (grant no. 81870799), the Key Research and Development Plan of Jiangsu Province (grant no. BE2019728), the Jiangsu Provincial Medical Youth Talent (grant no. QNRC2016850), the Southeast University-Nanjing Medical University Cooperative Research Project (grant no. 2242017K3DN14), the Nanjing Medical University-SUYAN Group Intelligent Innovation Research and Development Project (grant no. NMU-SY201806), the Science and Technology Development Foundation of Nanjing Medical University (grant no. 2017NJMU217) and the Foundation of Priority Academic Program Development of Jiangsu Higher Education Institutions (grant no. 2018-87).

\section{Availability of data and materials}

The datasets used and/or analyzed during the current study are available from the corresponding author on reasonable request.

\section{Authors' contributions}

WQZ contributed to the design, data acquisition and analysis and drafted the manuscript. PPM and SMZ contributed to the experiments performance, data acquisition and analysis. JQ contributed to the conception, design, data interpretation in the present study and critically revised the manuscript. All authors agreed to be accountable for all aspects of the work. All authors read and approved the final manuscript.

\section{Ethics approval and consent to participate}

Not applicable. 


\section{Patient consent for publication}

Not applicable.

\section{Competing interests}

The authors declare that they have no competing interests.

\section{References}

1. Ahn TK, Lee DH, Kim TS, Jang GC, Choi S, Oh JB, Ye G and Lee S: Modification of titanium implant and titanium dioxide for bone tissue engineering. Adv Exp Med Biol 1077: 355-368, 2018.

2. Zhang X, Geng H, Gong L, Zhang Q, Li H, Zhang X, Wang Y and Gao P: Modification of the surface of titanium with multifunctional chimeric peptides to prevent biofilm formation via inhibition of initial colonizers. Int J Nanomedicine 13: 5361-5375, 2018.

3. Zhu WQ, Shao SY, Xu LN, Chen WQ, Yu XY, Tang KM, Tang ZH, Zhang FM and Qiu J: Enhanced corrosion resistance of zinc-containing nanowires-modified titanium surface under exposure to oxidizing microenvironment. J Nanobiotechnology 17: $55,2019$.

4. Revathi A,Borrás AD, Muñoz AI, Richard C and Manivasagam G: Degradation mechanisms and future challenges of titanium and its alloys for dental implant applications in oral environment. Mater Sci Eng C Mater Biol Appl 76: 1354-1368. 2017.

5. Silva TSO, Freitas AR, Pinheiro MLL, do Nascimento C, Watanabe $\mathrm{E}$ and Albuquerque RF: Oral biofilm formation on different materials for dental implants. J Vis Exp 24: 57756, 2018.

6. Puskar T, Jevremovic D, Williams RJ, Eggbeer D, Vukelic D and Budak I: A comparative analysis of the corrosive effect of artificial saliva of variable $\mathrm{pH}$ on DMLS and Cast Co-Cr-Mo dental alloy. Materials (Basel) 7: 6486-6501, 2014.

7. Noronha Oliveira M, Schunemann WVH, Mathew MT, Henriques B, Magini RS, Teughels W and Souza JCM: Can degradation products released from dental implants affect peri-implant tissues? J Periodontal Res 53: 1-11, 2017.

8. Golasik M, Herman M and Piekoszewski W: Toxicological aspects of soluble titanium-a review of in vitro and in vivo studies. Metallomics 8: 1227-1242, 2016.

9. Wachi T, Shuto T, Shinohara Y, Matono Y and Makihira S: Release of titanium ions from an implant surface and their effect on cytokine production related to alveolar bone resorption. Toxicology 327: 1-9, 2015.

10. Wang Z, Deng Z, Gan J,Zhou G, Shi T, Wang Z, Huang Z, Qian H, Bao N, Guo T, et al: $\mathrm{TiAl}_{6} \mathrm{~V}_{4}$ particles promote osteoclast formation via autophagy-mediated downregulation of interferon-beta in osteocytes. Acta Biomater 48: 489-498, 2017.

11. Stegen $S$, van Gastel $N$, Eelen $G$, Ghesquière $B$, D'Anna $F$, Thienpont B, Goveia J, Torrekens S, Van Looveren R, Luyten FP, et al: HIF-1 $\alpha$ promotes glutamine-mediated redox homeostasis and glycogen-dependent bioenergetics to support postimplantation bone cell survival. Cell Metab 23: 265-279, 2016.

12. Yu Y, Newman H, Shen L, Sharma D, Hu G, Mirando AJ, Zhang H, Knudsen E, Zhang GF, Hilton MJ and Karner CM: Glutamine metabolism regulates proliferation and lineage allocation in skeletal stem cells. Cell Metab 29: 966-978.e4, 2019.

13. Fan Y, Hanai JI, Le PT, Bi R, Maridas D, DeMambro V, Figueroa CA, Kir S, Zhou X, Mannstadt M, et al: Parathyroid hormone directs bone marrow mesenchymal cell fate. Cell Metab 25: 661-672, 2017.

14. Li JY, D'Amelio P, Robinson J, Walker LD, Vaccaro C, Luo T, Tyagi AM, Yu M, Reott M, Sassi F, et al: IL-17A is increased in humans with primary hyperparathyroidism and mediates PTH-induced bone loss in mice. Cell Metab 22: 799-810, 2015.

15. Hayashi M, Nakashima T, Yoshimura N, Okamoto K, Tanaka S and Takayanagi H: Autoregulation of osteocyte Sema3A orchestrates estrogen action and counteracts bone aging. Cell Metab 29: 627-637, 2019

16. Miron RJ and Bosshardt DD: OsteoMacs: Key players around bone biomaterials. Biomaterials 82: 1-19, 2016.
17. Zhao S, Sun Y, Li X, Wang J, Yan L, Zhang Z, Wang D, Dai J, He J and Wang S: Scutellarin inhibits RANKL-mediated osteoclastogenesis and titanium particle-induced osteolysis via suppression of NF- $\kappa \mathrm{B}$ and MAPK signaling pathway. Int Immunopharmacol 40: 458-465, 2016.

18. Berger JM, Singh P, Khrimian L, Morgan DA, Chowdhury S, Arteaga-Solis E, Horvath TL, Domingos AI, Marsland AL, Yadav VK, et al: Mediation of the acute stress response by the skeleton. Cell Metab 30: 890-902 e8, 2019.

19. Lee H,Li C,Zhang Y,Zhang D, Otterbein LE and Jin Y: Caveolin-1 selectively regulates microRNA sorting into microvesicles after noxious stimuli. J Exp Med 216: 2202-2220, 2019.

20. Zhu WQ, Ming PP, Qiu J, Shao SY, Yu YJ, Chen JX, Yang J, $\mathrm{Xu}$ LN, Zhang SM and Tang CB: Effect of titanium ions on the $\mathrm{Hippo/YAP}$ signaling pathway in regulating biological behaviors of MC3T3-E1 osteoblasts. J Appl Toxicol 38: 824-833, 2018.

21. Chai S, Wan L, Wang JL, Huang JC and Huang HX: Gushukang inhibits osteocyte apoptosis and enhances BMP-2/Smads signaling pathway in ovariectomized rats. Phytomedicine 64 153063, 2019

22. Jimi E: The role of BMP signaling and NF- $\kappa B$ signaling on osteoblastic differentiation, cancer development, and vascular diseases-is the activation of NF- $\mathrm{KB}$ a friend or foe of BMP function? Vitam Horm 99: 145-170, 2015.

23. Lerner UH and Ohlsson C: The WNT system: Background and its role in bone. J Intern Med 277: 630-649. 2015

24. Xu C, Wang J, Zhu T, Shen Y, Tang X, Fang L and Xu Y: Cross-talking between PPAR and WNT signaling and its regulation in mesenchymal stem cell differentiation. Curr Stem Cell Res Ther 11: 247-254, 2016.

25. Jia L, Zhang Y, Ji Y, Xiong Y, Zhang W, Wen Y and Xu X: YAP balances the osteogenic and adipogenic differentiation of hPDLSCs in vitro partly through the Wnt $/ \beta$-catenin signaling pathway. Biochem Biophys Res Commun 518: 154-160, 2019.

26. Zhu WQ, Yu YJ, Xu LN, Ming PP, Shao SY and Qiu J: Regulation of osteoblast behaviors via cross-talk between Hippo/YAP and MAPK signaling pathway under fluoride exposure. J Mol Med (Berl) 97: 1003-1017, 2019.

27. Zheng W, Gu X, Hu D and Hao Y: Co-culture with synovial tissue in patients with rheumatoid arthritis suppress cell proliferation by regulating MAPK pathway in osteoblasts. Am J Transl Res 11: 3317-3327, 2019.

28. Chen J, Cao J and Luo Y: Expression of ERK and p-ERK proteins of ERK signaling pathway in the kidneys of fluoride-exposed carp (Cyprinus carpio). Acta Histochem 116: 1337-1341, 2014.

29. Huang D, Li X, Sun L, Huang P, Ying H, Wang H, Wu J and Song H: Regulation of Hippo signalling by p38 signalling. J Mol Cell Biol 8: 328-337, 2016.

30. Cao, Chen J, Xie L, Wang J, Feng C and Song J: Protective properties of sesamin against fluoride-induced oxidative stress and apoptosis in kidney of carp (Cyprinus carpio) via JNK signaling pathway. Aquat Toxicol 167: 180-190, 2015

31. Mizerska-Kowalska M, Slawinska-Brych A, Kalawaj K,Żurek A, Pawińska B, Rzeski W and Zdzisińska B: Betulin promotes differentiation of human osteoblasts in vitro and exerts an osteoinductive effect on the hFOB 1.19 cell line through activation of JNK, ERK1/2, and mTOR kinases. Molecules 24: 2637-2653, 2019.

32. Balera Brito VG, Chaves-Neto AH, Landim de Barros $\mathrm{T}$ and Penha Oliveira SH: Soluble yerba mate (Ilex Paraguariensis) extract enhances in vitro osteoblastic differentiation of bone marrow-derived mesenchymal stromal cells. J Ethnopharmacol 244: 112131, 2019.

33. Kawabata T, Tokuda H, Fujita K, Matsushima-Nishiwaki R, Sakai G, Tachi J, Hioki T, Kim W, Iida H, Otsuka T and Kozawa O: HSP90 inhibitors diminish PDGF-BB-induced migration of osteoblasts via suppression of p44/p42 MAP kinase. Biomed Res 40: 169-178, 2019.

34. Hayes JS, Khan IM, Archer CW and Richards RG: The role of surface microtopography in the modulation of osteoblast differentiation. Eur Cell Mater 20: 98-108, 2010.

35. Glynn ER, Londono AS, Zinn SA, Hoagland TA and Govoni KE: Culture conditions for equine bone marrow mesenchymal stem cells and expression of key transcription factors during their differentiation into osteoblasts. J Anim Sci Biotechnol 4: 40, 2013.

36. Komori T: Regulation of osteoblast differentiation by transcription factors. J Cell Biochem 99: 1233-1239, 2006.

37. Ting M, Craig J, Balkin BE and Suzuki JB: Peri-implantitis: A Comprehensive overview of systematic reviews. J Oral Implantol 44: 225-247, 2018. 
38. Romanos GE, Delgado-Ruiz R and Sculean A: Concepts for prevention of complications in implant therapy. Periodontol 2000 81: 7-17, 2019.

39. Di Laura A, Hothi HS, Meswania JM, Whittaker RK, de Villiers D, Zustin J, Blunn GW, Skinner JA and Hart AJ: Clinical relevance of corrosion patterns attributed to inflammatory cell-induced corrosion: A retrieval study. J Biomed Mater Res B Appl Biomater 105: 155-164, 2017.

40. Yu WQ, Qiu J and Zhang FQ: In vitro corrosion study of different $\mathrm{TiO} 2$ nanotube layers on titanium in solution with serum proteins. Colloids Surf B Biointerfaces 84: 400-405, 2011.

41. Noumbissi S, Scarano A and Gupta S: A literature review study on atomic ions dissolution of titanium and its alloys in implant dentistry. Materials (Basel) 12: 368, 2019.

42. Mercan S, Bölükbaşı N, Bölükbaşı MK, Yayla M and Cengiz S Titanium element level in peri-implant mucosa. Biotechnol Biotechnol Equip 27: 4002-4005, 2014.

43. Messer RL, Tackas G, Mickalonis J, Brown Y, Lewis JB and Wataha JC: Corrosion of machined titanium dental implants under inflammatory conditions. J Biomed Mater Res B App Biomater 88: 474-481, 2009.

44. Vallés G, González-Melendi P, González-Carrasco JL, Saldaña L, Sánchez-Sabaté E, Munuera L and Vilaboa N: Differential inflammatory macrophage response to rutile and titanium particles. Biomaterials 27: 5199-5211, 2006.

45. Costa V, Carina V, Fontana S, De Luca A, Monteleone F, Pagani S, Sartori M, Setti S, Faldini C, Alessandro R, et al: Osteogenic commitment and differentiation of human mesenchymal stem cells by low-intensity pulsed ultrasound stimulation. J Cell Physiol 233: 1558-1573, 2018.

46. Zou W, Greenblatt MB, Brady N, Lotinun S, Zhai B, de Rivera H, Singh A, Sun J, Gygi SP, Baron R, et al: The microtubule-associated protein DCAMKL1 regulates osteoblast function via repression of Runx2. J Exp Med 210: 1793-1806, 2013.

47. Maehata Y, Takamizawa S, Ozawa S, Kato Y, Sato S, Kubota E and Hata R: Both direct and collagen-mediated signals are required for active vitamin D3-elicited differentiation of human osteoblastic cells: Roles of osterix, an osteoblast-related transcription factor. Matrix Biol 25: 47-58, 2006.

48. Zhou W, Zhang J, Lin K and Chen F: Comparison between mandibular and femur derived bone marrow stromal cells: Osteogenic and angiogenic potentials in vitro and bone repairing ability in vivo. RSC Adv 7: 56220-56228, 2017.

49. Zhang DD, Wu YF, Chen WX, Xu Y, Liu SY, Luo HH, Jiang GM, $\mathrm{Wu}$ Y and $\mathrm{Hu} \mathrm{P}$ : C-type natriuretic peptide attenuates renal osteodystrophy through inhibition of FGF-23/MAPK signaling. Exp Mol Med 51: 70, 2019.
50. Chen M, Chen PM, Dong QR, Huang Q, She C and Xu W: p38 Signaling in titanium particle-induced MMP-2 secretion and activation in differentiating MC3T3-E1 cells. J Biomed Mater Res A 102: 2824-2832, 2014.

51. Li K, Yang F, Zhang G, Song S, Li Y, Ren D, Miao Y and Song CP AIK1, a mitogen-activated protein kinase, modulates abscisic acid responses through the MKK5-MPK6 kinase cascade. Plant Physiol 173: 1391-1408, 2017.

52. Wang C, Sun H and Zhong Y: Notoginsenoside R1 promotes MC3T3-E1 differentiation by up-regulating miR-23a via MAPK and JAK1/STAT3 pathways. Artif Cells Nanomed Biotechnol 47: 603-609, 2019.

53. Ewendt $\mathrm{F}$ and Föller M: p38MAPK controls fibroblast growth factor 23 (FGF23) synthesis in UMR106-osteoblast-like cells and in IDG-SW3 osteocytes. J Endocrinol Invest 42: 1477-1483, 2019.

54. Liu S, Parameswaran H, Young SM and Varisco BM: JNK suppresses pulmonary fibroblast elastogenesis during alveolar development. Respir Res 15: 34, 2014.

55. Fleming Y, Armstrong CG, Morrice N, Paterson A, Goedert M and Cohen P: Synergistic activation of stress-activated protein kinase 1/c-Jun N-terminal kinase (SAPK1/JNK) isoforms by mitogen-activated protein kinase kinase 4 (MKK4) and MKK7. Biochem J: 145-154, 2000.

56. Chen K, Ng PY, Chen R, Hu D, Berry S, Baron R and Gori F: Sfrp4 repression of the Ror $2 /$ Jnk cascade in osteoclasts protects cortical bone from excessive endosteal resorption. Proc Natl Acad Sci USA 116: 14138-14143, 2019.

57. Ouyang Z, Huang Q, Liu B, Wu H, Liu T and Liu Y: Rubidium chloride targets Jnk/p38-mediated NF- $\kappa$ B activation to attenuate osteoclastogenesis and facilitate osteoblastogenesis. Front Pharmacol 10: 584, 2019.

58. Gao P, Wang H, Liu J, Wu Y, Hei W, He Z, Cai C, Guo X, Cao G and $\mathrm{Li} \mathrm{B}: \mathrm{miR}-128$ regulated the proliferation and autophagy in porcine adipose-derived stem cells through targeting the JNK signaling pathway. J Recept Signal Transduct Res: 1-6, 2020 (Online ahead of print).

59. Mulder SE, Dasgupta A, King RJ, Abrego J, Attri KS, Murthy D, Shukla SK and Singh PK: JNK signaling contributes to skeletal muscle wasting and protein turnover in pancreatic cancer cachexia. Cancer Lett 491: 70-77, 2020 (Online ahead of print).

This work is licensed under a Creative Commons Attribution-NonCommercial-NoDerivatives 4.0 International (CC BY-NC-ND 4.0) License. 